\title{
Fat embolism due to bilateral femoral fracture: a case report
}

This article was published in the following Dove Press journal:

International Journal of General Medicine

13 January 2012

Number of times this article has been viewed

\author{
Konstantinos Porpodis' \\ Michael Karanikas ${ }^{2}$ \\ Paul Zarogoulidis' \\ Maria Konoglou ${ }^{3}$ \\ Kalliopi Domvri \\ Alexandros Mitrakas ${ }^{2}$ \\ Panagiotis Boglou 4 \\ Stamatia Bakali ${ }^{5}$ \\ Alkis lordanidis ${ }^{6}$ \\ Vasilis Zervas' \\ Nikolaos Courcoutsakis ${ }^{6}$ \\ Nikolaos Katsikogiannis ${ }^{7}$ \\ Konstantinos Zarogoulidis' \\ 'Pulmonary Department, \\ "G Papanikolaou" General Hospital, \\ Aristotle University of Thessaloniki, \\ Thessaloniki, ${ }^{2}$ Ist Surgery \\ Department, University General \\ Hospital of Alexandroupolis, \\ Democritus University of Thrace, \\ Alexandroupolis, ${ }^{3}$ Ist Pulmonary \\ Department, "G Papanikolaou" \\ General Hospital, Thessaloniki, \\ Greece; ${ }^{4}$ Pulmonary Department. \\ ${ }^{5}$ Microbiology Department, ${ }^{6}$ Radiology \\ Department, University General \\ Hospital of Alexandroupolis, \\ Democritus University of Thrace, \\ Alexandroupolis, Greece; ${ }^{7}$ Surgery \\ Department (NHS), University \\ General Hospital of Alexandroupolis, \\ Alexandroupolis, Greece
}

Correspondence: Paul Zarogoulidis Pulmonary Department, "G Papanikolaou" General Hospital, Aristotle University of Thessaloniki, Thessaloniki 54I 24, Greece

$\mathrm{Tel}+3023 \mathrm{I} 0992433$

$\mathrm{Fax}+302310992433$

Email pzarog@hotmail.com
Abstract: Fat embolism syndrome is usually associated with surgery for large bone fractures. Symptoms usually occur within 36 hours of hospitalization after traumatic injury. We present a case with fat embolism syndrome due to femur fracture. Prompt supportive treatment of the patient's respiratory system and additional pharmaceutical treatment provided the positive clinical outcome. There is no specific therapy for fat embolism syndrome; prevention, early diagnosis, and adequate symptomatic treatment are very important. Most of the studies in the last 20 years have shown that the incidence of fat embolism syndrome is reduced by early stabilization of the fractures and the risk is even further decreased with surgical correction rather than conservative management.

Keywords: fat embolism syndrome, trauma, femur fracture, ARDS

\section{Introduction}

A fat embolus is a fat particle that enters the circulatory system causing vascular occlusion. Fat emboli can cause a more serious condition called fat embolism syndrome (FES), in which circulating fat emboli or macroglobules result in multisystem dysfunction. ${ }^{1}$ In different studies, the incidence of FES ranges from $<1 \%$ to $29 \%$, but the exact incidence has not yet been determined. ${ }^{2,3}$

Approximately $90 \%$ of the cases are associated with trauma, especially fracture or surgery of a large bone, such as the femur. As a result of the disrupted bone, the bone marrow fat escapes into circulation. Although this may be a cause, fat embolism may also occur due to conditions such as extensive trauma or syndromes that modify lipid metabolism. ${ }^{3}$

Symptoms of fat embolism usually occur 12-36 hours after a traumatic injury. ${ }^{4}$ Pulmonary dysfunction (dyspnea, tachypnea, hypoxemia) is the primary manifestation, occurring in $75 \%$ of cases. ${ }^{5} \mathrm{Up}$ to $10 \%$ of cases may develop respiratory failure and $5 \%-8 \%$ of patients may progress to the severe acute respiratory distress syndrome (ARDS). ${ }^{6}$ In cases with bilateral fractures, the incidence of ARDS has been reported to be higher than for single fractures, reaching almost $43 \%{ }^{7}$ Half of FES patients develop severe hypoxemia and respiratory insufficiency requiring mechanical ventilation. ${ }^{8}$ However, the role of fat emboli as a cause of ARDS after injury has not yet been defined. ${ }^{9}$

Neurological features (agitation, delirium, seizures or coma) are seen in $86 \%$ of patients with FES. ${ }^{10}$ Dermatological dysfunction is developed as a nonpalpable petechial rash in the conjunctiva, axilla, chest, and neck in up to $60 \%$ of cases. ${ }^{11}$ 
Some other minor symptoms that may also be present are: anemia, low platelets, tachycardia, pyrexia, myocardial depression, and renal changes (eg, oliguria or hematuria). ${ }^{5}$

Clinical findings are important in diagnosing FES, while biochemical changes may also be of value. The most common classification scheme for diagnosis is that of Gurd and Wilson, providing major and minor diagnostic criteria (Table 1), according to which, diagnosis of FES requires the presence of at least one major and four minor criteria. ${ }^{5}$

The reliability of these criteria has been questioned and other schemes have been proposed based on the involvement of the respiratory system alone (Table 1). ${ }^{12}$ More recently, Schonfeld et $\mathrm{al}^{13}$ proposed a semiquantitative measure to diagnose FES, as proposed by Lindeque et al, ${ }^{12}$ in which a score of more than five is required for a positive diagnosis (Table 2).

\section{Case report}

A 20-year-old male was transferred to the emergency room after a car accident. The patient suffered bilateral closed femoral fractures (stage II) and was hemodynamically stable, without any deterioration of consciousness. Chest radiography and arterial blood gas analysis revealed normal findings. Nine hours later, reamed femoral nailing was performed bilaterally. Twenty-four hours after admission, the patient manifested tachycardia ( $>110 /$ minute), dyspnea, and hypoxemia $\left(\mathrm{PO}_{2}=74 \mathrm{mmHg}, \mathrm{PaCO}_{2}=35 \mathrm{mmHg}, \mathrm{pH}=7.44\right)$. The blood test results were normal but because the $\mathrm{D}$-dimer levels were elevated, a spiral computed tomography (CT) scan was performed for greater visualization of pulmonary vessels.

The spiral chest CT scan revealed peripheral emboli and mild pleural effusion in both hemithoraxes (Figure 2). The echocardiography showed normal systolic function (ejection fraction $=60 \%-70 \%$ ) and moderate right ventricular dilatation. These findings excluded the occurrence of cardiogenic pulmonary edema, but the suspicion of pulmonary embolism

Table I Gurd and Wilson's criteria ${ }^{5}$

\begin{tabular}{|c|c|}
\hline Major features & Minor features \\
\hline $\begin{array}{l}\text { Axillary or subconjunctival } \\
\text { petechiae }\end{array}$ & Tachycardia $>110 /$ minute \\
\hline $\begin{array}{l}\text { Hypoxemia } \mathrm{PaO}_{2}<60 \mathrm{mmHg} \\
\mathrm{FIO}_{2}=0.4\end{array}$ & Pyrexia $>38.5$ \\
\hline Pulmonary edema & Retinal fat or petechiae \\
\hline Sudden drop in $\mathrm{Hb}$ level $>20 \%$ & Urinary fat globules or oligoanuria \\
\hline $\begin{array}{l}\text { Central nervous system depression } \\
\text { disproportionate to hypoxemia }\end{array}$ & $\begin{array}{l}\text { Sudden thrombocytopenia }>50 \% \\
\text { High ESR }>71 \mathrm{~mm} / \text { hour }\end{array}$ \\
\hline
\end{tabular}

Abbreviation: ESR, erythrocyte sedimentation rate.
Table 2 Lindeque's criteria ${ }^{12}$

- A sustained $\mathrm{PaO}_{2}<8 \mathrm{kPa}(60 \mathrm{mmHg})$

- A sustained $\mathrm{PaCO}_{2}>7.3 \mathrm{kPa}(55 \mathrm{mmHg})$ or $\mathrm{pH}<7.3$

- A sustained respiratory rate $>35 /$ minute even after adequate sedation

- Increased work of breathing judged by dyspnea, use of accessory

muscles, tachycardia and anxiety

emerged. The patient was put on supplemental oxygen and heparin IV, but gradually his clinical status deteriorated. Forty-eight hours after admission, he developed widespread petechiae on the chest and respiratory failure $\left(\mathrm{PO}_{2}=51 \mathrm{mmHg}\right.$, $\mathrm{PaCO}_{2}=33 \mathrm{mmHg}, \mathrm{pH}=7.47, \mathrm{FIO}_{2}=21 \%$ ). Chest X-ray radiography showed the appearance of ARDS, requiring mechanical ventilation of the patient (Figure 1).

The combination of long-bone fracture, petechial rash, hypoxemia, tachycardia, and the rapid onset of ARDS within 24-48 hours after surgery prompted a diagnosis of FES. With supportive treatment in the intensive care unit (ICU), good hydration, and cortisone therapy $(100 \mathrm{mg} \times 3)$ for 10 days, the patient subsequently improved. On the patient's second day in the ICU, cerebral and pelvic CT scans were also performed showing normal findings. The patient remained in the ICU for a period of 10 days until extubation on day 12. On this same day he was transferred to the pulmonary department with good oxygenation and hemodynamic stablity. He was discharged from the hospital 5 days later.

\section{Discussion}

Fat embolism is most commonly associated with skeletal injury and is most likely to occur in patients with multiple long-bone and pelvic fractures. Some other traumatic causes include: rib fractures, massive soft tissue injury, severe burns, bone marrow biopsy, and liposuction. More rarely, fat embolism is also associated with some nontraumatic disorders, such as pancreatitis, diabetes mellitus, and high-dose steroid therapy. ${ }^{14}$

Additionally, a few related studies report that the factors that increase the risk of FES's development are: young age, closed fractures, multiple fractures, and conservative therapy for long-bone fractures. ${ }^{13,15}$ The risk of fat embolism in bilateral femoral fractures is higher than in isolated long-bone fractures. Patients with bilateral femoral fractures have a higher mortality rate than those with single femoral fractures. ${ }^{16}$ Overall mortality is estimated at 5\%-15\% and up to $36 \%$ in patients who require mechanical ventilation. ${ }^{3,17}$

For the development of FES, a mechanical theory and a biochemical theory have been proposed. According to the mechanical theory, FES occurs when large fat globules enter 


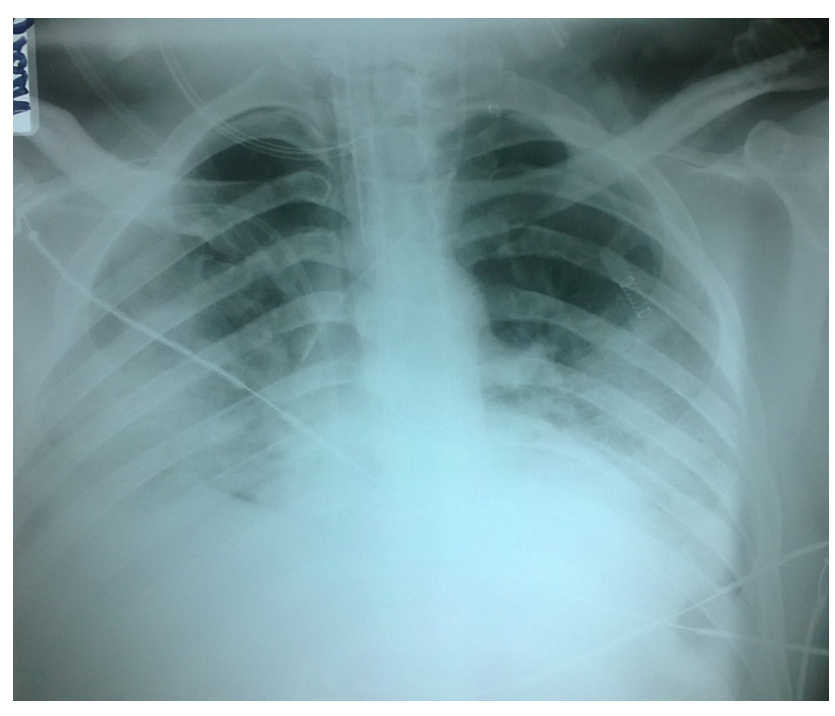

Figure I Chest X-ray showing acute respiratory distress syndrome.

the venous circulation resulting in the obstruction of the pulmonary vascular system. However, this theory cannot substantiate the delay in the development of symptoms. ${ }^{18}$

The biochemical theory suggests that hormonal changes after extensive trauma induce hydrolysis of triglycerides and release of free fatty acids, causing toxic endothelium damage in pulmonary capillary beds, as well as ARDS in animal models. ${ }^{19}$ In this theory, the time required to produce these toxic intermediaries explains the delay in development of symptoms. Despite the large number of studies supporting the involvement of these mechanisms in the development of FES, evidence is considered circumstantial. ${ }^{13,15,17}$

Among the reasons for the difficulty in diagnosis of FES is the complication of widely different clinical conditions that may vary in severity. Diagnosis is established on the basis of patients' clinical condition and symptoms, using the process of exclusion for other possible causes. The most useful examination in diagnosing FES includes imaging studies such as chest radiography, $\mathrm{CT}$ scans, pulmonary ventilation/perfusion scans, and cerebral magnetic resonance imaging, as well as cardiac investigations so as to exclude cardiac causes. In our case, the diagnosis of FES was prompted on the basis of rapid onset of ARDS (Figure 1) and petechial rash combined with the existing hypoxemia and tachycardia, with no evidence of sepsis, cardiogenic pulmonary edema, or other causes of ARDS. Even though these symptoms met only two major and one minor criteria of Gurd and Wilson's classification, they totaled 14 points in Schonfeld's classification. These findings confirm the results of previous studies suggesting that many of the major and minor criteria of FES may be outdated or nonspecific regarding ARDS..$^{20}$

The treatment of fat embolism is only supportive and includes maintenance of adequate oxygenation, stable hemodynamics, normal blood levels, hydration, prevention of deep venous thrombosis and gastrointestinal bleeding, and nutrition.

The purpose of medication is to reduce morbidity and prevent complications. High-dose corticosteroids have been effective in preventing the development of FES in several studies, but the use of corticosteroid prophylaxis remains controversial. ${ }^{21}$ Albumin has also been recommended because it not only restores blood levels but also combines the fatty acids that may limit lung injury. ${ }^{22}$

The timing and the type of surgery for fractures constitute modifiable factors for the development of FES. Previous studies have revealed that after a traumatic injury, early surgical fixation in patients with isolated femoral fractures could prevent the development of FES. Interestingly, in a study of 60 cases that underwent surgery within 10 hours of injury, none of the patients was diagnosed with FES. ${ }^{23}$ However, in our case, even though early surgical stabilization was performed 10 hours after injury, the development of FES was not prevented. Consequently, early surgery in bilateral femoral fractures may not

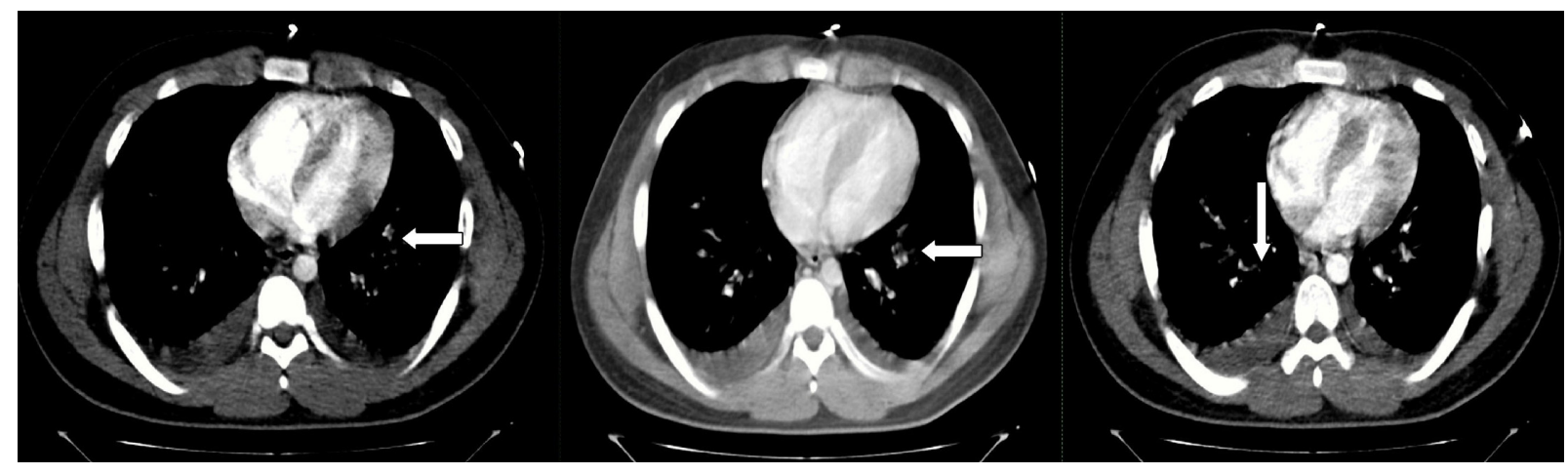

Figure 2 Peripheral emboli arrows indicate fat emboli and mild pleural effusion in both hemithoraxes. 
have as positive an influence as seen in previous cases of single femoral fractures. Therefore, it was considered that bilateral fractures have a greater magnitude of injury and may cause a more severe impact to the immune system.

On the other hand, a number of studies have pointed out that surgical orthopedic treatment, especially intramedullary nailing, is associated with a higher probability of fat embolism and pulmonary complications such as ARDS. Reamed intramedullary nailing, performed in our patient, is the preferred method for stabilization of femoral shaft fractures; ${ }^{24}$ yet, it has been shown to cause systemic complications due to the release of fat emboli from the bone marrow of the medullary canal. ${ }^{25}$ Moreover, the absence of other causative factors of pulmonary dysfunction (aspiration, previous pulmonary disease), led to the hypothesis that the procedure of intramedullary stabilization triggers the development of FES postoperatively.

In summary, there is no specific therapy for FES; prevention, early diagnosis, and adequate symptomatic treatment are very important. Most of the studies in the last 20 years have shown that the incidence of FES is reduced by early stabilization of the fractures and the risk is even further decreased with surgical correction rather than conservative management. ${ }^{26}$ In the present study, the bilateral femoral fractures and intramedullary stabilization were assumed to be the most significant factors responsible for the development of FES postoperatively.

\section{Conclusion}

The diagnosis of FES may be complex because there are no pathognomonic signs (except for the petechiae). Early suspicion combined with chest radiography and cerebral CT is the key answer to diagnosis. Bilateral fractures should be approached for damage management with the principles of orthopedics in order to eliminate potential complications. As the literature to date is limited, further research is needed to investigate the controversial relationship of bilateral femoral fractures and FES.

\section{Consent}

Written informed consent was obtained from the patient upon discharge for publication of this case report and all accompanying images.

\section{Authors' contributions}

All authors contributed equally to the preparation of the manuscript.

\section{Disclosure}

The authors report no conflicts of interest in this work.

\section{References}

1. Johnson MJ, Lucas GL. Fat embolism syndrome. Orthopedics. 1996; 19(1):41-48.

2. Shaikh N. Emergency management of fat embolism syndrome. JEmerg Trauma Shock. 2009;2(1):29-33.

3. Mellor A, Soni N. Fat embolism. Anaesthesia. 2001;56(2):145-154.

4. Carr J, Hansen S. Fulminant fat embolism. Orthopedics. 1990;13(2): 258-261.

5. Carlson DS, Pfadt E. Fat embolism syndrome. Nursing. 2011; 41(4):72.

6. Fowler AA, Hamman RF, Good JT, et al. Adult respiratory distress syndrome: risk with common predispositions. Ann Int Med. 1983; 98(5 Pt 1):593-597.

7. Raman R, Sidhom S, Pape HC, et al. Systemic effects of bilateral tibial versus bilateral femoral shaft fractures. Is there a difference? Acta Orthop Belg. 2004;70(2):134-141.

8. King MB, Harmon KR. Unusual forms of pulmonary embolism. Clin Chest Med. 1994;15(3):561-580.

9. Christie J, Robinson CM, Pell ACH, McBirnie J, Burnett R. Transcardiac echocardiography during invasive intramedullary procedures. $J$ Bone Joint Surg Br. 1995;77(3):450-455

10. Byrick RJ. Fat embolism and postoperative coagulopathy. Can $J$ Anaesth. 2001;48(7):618-621.

11. Kaplan RP, Grant JN, Kaufman AJ. Dermatologic features of the fat embolism syndrome. Cutis. 1986;38(1):52-55.

12. Lindeque BG, Schoeman HS, Dommissen GF, Boeyens MC, Vlok AL. Fat embolism syndrome: a double blind therapeutic study. J Bone Joint Surg Br. 1987;69(1):128-131

13. Schonfeld SA, Ploysongsang Y, DiLisio R, et al. Fat embolism prophylaxis with corticosteroid: A prospective study in high-risk patients. Ann Int Med. 1983;99(4):438-443.

14. Shapiro MP, Hayes JA. Fat embolism in sickle cell disease: Report of a case with brief review of literature. Arch Intern Med. 1984;144(1): 181-182.

15. Dillerud E. Abdominoplasty combined with suction lipoplasty: A study of complications, revision and risk factors in 487 cases. Ann Plast Surg. 1990;25(5):333-338.

16. Nork SE, Agel J, Russell GV, et al. Mortality after reamed intramedullary nailing of bilateral femur fractures. Clin Orthop Relat Res. 2003;(415):272-278

17. Wildsmith JA, Masson AH. Severe fat embolism: a review of 24 cases. Scott Med J. 1978;23(2):141-148.

18. Gossling HR, Pellegrini VD Jr. Fat embolism syndrome: A review of pathology and physiological basis of treatment. Clin Orthop Relat Res. 1982;(165):68-82.

19. Schemitsch EH, Turchin DG, Anderson GI, et al. Pulmonary and systemic fat embolization after medullary canal pressurization: a hemodynamic and histologic investigation in the dog. $J$ Trauma. 1998;45(4):738-742.

20. Robinson CM. Current concepts of respiratory insufficiency syndromes after fracture. J Bone Joint Surg Br. 2001;83(6):781-791.

21. Enneking FK. Cardiac arrest during total knee replacement. $J$ Clin Anaesth. 1995;7(3):253-263

22. McDermott ID, Culpan P, Clancy M, Dooley JF. The role of rehydration in prevention of FES. Injury. 2002;33(9):757-759.

23. Pinney SJ, Keating JK, Meclk RN. Fat embolism syndrome in isolated femoral fracture. Injury. 1998;29(2):131-133.

24. Bone LB, Johnson KD, Weigelt J, Scheinberg R. Early versus delayed stabilization of fractures. J Bone Joint Surg Am. 1989;71(3):336-340.

25. Wenda K, Runkel M, Degreif J, Ritter G. Pathogenesis and clinical relevance of bone marrow embolism in medullary nailing demonstrated by intraoperative echocardiography. Injury. 1993;24 Suppl 3: S73-S81.

26. Kim YH, Oh SW, Kim JS. Prevalence of fat embolism following bilateral simultaneous and unilateral total hip arthroplasty performed with or without cement: a prospective, randomized clinical study. J Bone Joint Surg Am. 2002;84-A(8):1372-1379. 
International Journal of General Medicine

Dovepress

\section{Publish your work in this journal}

The International Journal of General Medicine is an international, peer-reviewed open-access journal that focuses on general and internal medicine, pathogenesis, epidemiology, diagnosis, monitoring and treatment protocols. The journal is characterized by the rapid reporting of reviews, original research and clinical studies across all disease areas.
A key focus is the elucidation of disease processes and management protocols resulting in improved outcomes for the patient.The manuscript management system is completely online and includes a very quick and fair peer-review system. Visit http://www.dovepress.com/ testimonials.php to read real quotes from published authors.

Submit your manuscript here: http://www.dovepress.com/international-journal-of-general-medicine-journal 